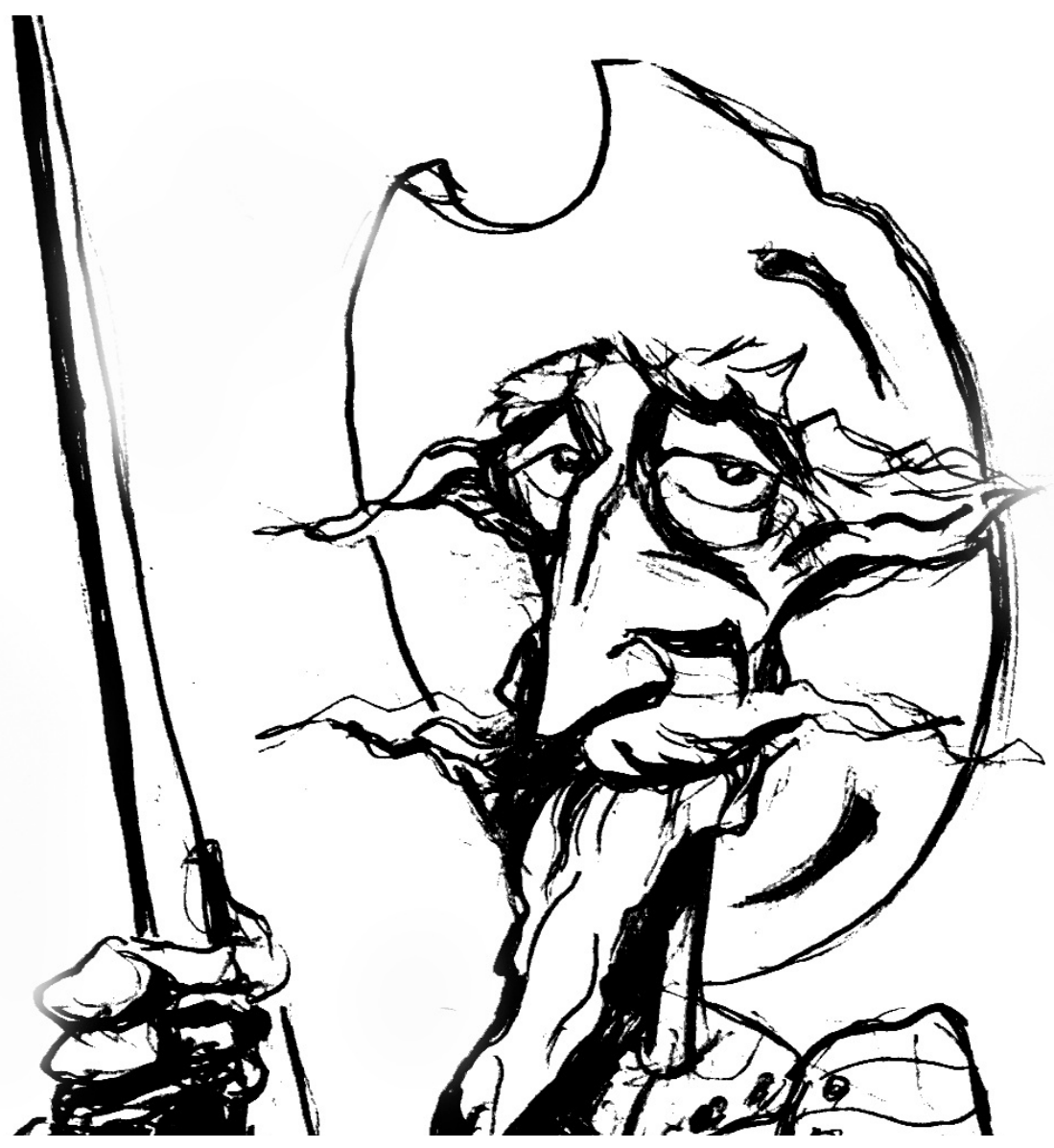

La territorialidad en disputa: La construcción de espacios políticos en un área marginal del imperio español a fines del período colonial

[Carmen Susana Cantera] 



\title{
La territorialidad en disputa: La construcción de espacios políticos en un área marginal del imperio español a fines del período colonial $^{*}$
}

\author{
Territoriality in Dispute: The Construction of Political Spaces in a Marginal \\ Area of the Spanish Empire at the end of the Colonial Period
}

CARMEN SUSANA CANTERA

\section{Resumen}

El reformismo borbónico introdujo acciones de resguardo y poblamiento con el fin de "estabilizar" las fronteras. En la zona sur de la intendencia de Córdoba se fundaron fuertes principales y fortines intermedios que acompañaban el curso del río Cuarto y que dieron origen a pueblos que adquirieron la jerarquía de villa real y a las que se dotó de institución capitular. Este trabajo analiza cómo operaban estrategias tradicionales de ejercicio del poder en las comunidades locales que, representadas corporativamente en los cabildos, defendían y sustentaban sus prerrogativas frente a las imposiciones de las autoridades superiores.

\section{Palabras clave}

Territorio; conflict; corporativo; competencia política; poder

\begin{abstract}
In order to "stabilize" the borders, the bourbon reformism introduced protection and settlement actions. In the southern area of the Intendencia de Córdoba, major and intermediate forts were founded along the course of the Cuarto river. These forts gave rise to towns that acquired the hierarchy of a royal village and were provided with city councils (Cabildos). Hence, this work analyzes how traditional strategies of power exercise operated in local communities which, represented corporately in the Cabildos, defended and sustained their prerogatives against the impositions of higher authorities.
\end{abstract}

Key words

Territory; conflict; corporate; political competition; power

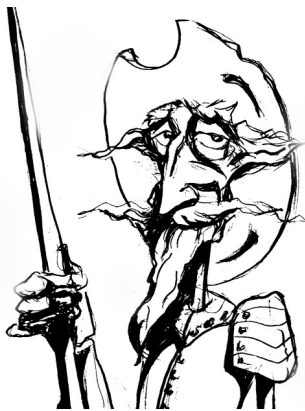

Recibido con pedido de publicación el 29 de julio de 2019

Aceptado para su publicación el 2 de octubre de 2019

Versión definitiva recibida el 20 de diciembre de 2019

Carmen Susana Cantera, Universidad Nacional de La Pampa, Santa Rosa, Argentina; e-mail: carmensusanacantera@gmail.com

\footnotetext{
* Agradezco los comentarios de los evaluadores anónimos de la revista

Esta obra se publica bajo licencia Creative Commons. Atribución-NoComercial-CompartirIgual $(\mathrm{cc})$ EY-NC-SA $\underline{4.0}$

Internacional

Cantera, Carmen Susana "La territorialidad en disputa: La construcción de espacios políticos en un área marginal del imperio español a fines del período colonial", Prohistoria, Año XXIII, núm. 33, jun. 2020, pp. 67-93.
} 


\section{A modo de introducción}

Durante el siglo XVIII el reformismo borbónico planteó una renovación en la partición política que incluyó acciones de resguardo y poblamiento con el fin de "estabilizar" las fronteras y crear un sistema defensivo que permitiera ampliar el espacio ocupado por la sociedad hispano-criolla. Dentro del Virreinato del Río de la Plata la ciudad de Córdoba se convirtió en cabecera de intendencia y en la zona sur de la jurisdicción se fundaron fuertes principales y fortines intermedios que acompañaban el curso del río Cuarto. Estos enclaves resultaron de importancia decisiva para la constitución de dos centros urbanos que adquirieron la jerarquía de villas bajo las denominaciones de Villa de la Concepción del Río Cuarto y Villa Real de La Carlota. En ambas se estableció la institución capitular y la segunda fue designada como sede de la comandancia general de frontera. ${ }^{1}$

La circulación mercantil con Cuyo y con Chile involucraba a ambos pueblos que fueron fundados en función de que por allí pasaba el antiguo camino real de Mendoza a Buenos Aires. Sin embargo fueron frecuentes las quejas de los vecinos que denunciaron ante el cabildo de la Concepción que el camino de postas se había desviado hacia el norte y obviaba el paso por ambos poblados. En 1811 se delimitaron cuáles serían los caminos utilizados en dirección a la ciudad de Córdoba y hacia Chile y se resolvió a favor de ambas villas una cuestión que se había dilatado por varios años.

A pesar de la relativa situación de subordinación que los pueblos poseían respecto de las autoridades que residían en las ciudades principales es posible advertir una dinámica propia que involucraba a diferentes ámbitos de decisión entre los que se evidencia el conflicto. En el marco de construcción del poder territorial, entendido este como el equipamiento político y administrativo del espacio, este trabajo analiza las diversas instancias en que los actores sociales se vincularon a través de alianzas y confrontaciones que dan cuenta de la competencia política. Las comunidades locales desplegaron estrategias tradicionales de ejercicio del poder a través de su representación corporativa en los cabildos. Asimismo defendían y sustentaban sus prerrogativas frente a las imposiciones de las autoridades superiores (gobernadores, virreyes, oidores) o de otra esfera jurisdiccional (comandantes de frontera).

Los acuerdos de cabildo, las antologías documentales y los expedientes del fondo gobierno del Archivo Histórico de la Provincia de Córdoba contienen información que permite indagar sobre la índole de los conflictos producidos

\footnotetext{
${ }^{1}$ La categoría de villa implicaba un ascenso en la condición jerárquica urbana. De acuerdo al Diccionario de Autoridades de la Real Academia Española se denominaba villa a "la población, que tiene algunos privilegios, con que se distingue de la Aldea, como vecindad, y jurisdicción separada de la Ciudad". Real Academia Española, Diccionario de Autoridades (1789).
} 
entre las diferentes instituciones del poder colonial y el modo en que se involucraban los individuos participantes. El desarrollo del artículo incluye un breve recorrido por los principales antecedentes historiográficos y el marco teórico-conceptual que permite encuadrar la problemática de la territorialización y de la construcción de espacios políticos. En el núcleo central se expone el tenor de los conflictos jurisdiccionales, la competencia política entre diferentes instancias de la administración y las alternativas de resolución de los mismos. ${ }^{2}$

\section{Antecedentes historiográficos}

María Rosa Carbonari (2010) refiere a que la preocupación académica por la historia de la región del río Cuarto se inició en la década de 1930 por parte de los eclesiásticos de diferentes órdenes que mostraron su preocupación por iluminar el rol evangelizador de la conquista española. Los clérigos fueron pioneros en la recopilación de documentos históricos. La historia oficial de vertiente nacionalista y política estuvo representada por la obra de Alfredo Vitulo quien, gracias a sus vínculos institucionales gestionó la publicación de las actas capitulares de la Villa de la Concepción (1798-1812) por parte de la Academia Nacional de la Historia en 1947.

Otro historiador regional que destaca Carbonari es Carlos Mayol Laferrere, quien creó el Instituto de Estudios Históricos que contó con una publicación periódica cuyos trabajos más significativos refieren a estudios genealógicos de los primeros pobladores de la región. Más recientemente Mayol Laferrere (2014) ha editado un libro que incluye las genealogías de los cabildantes de Concepción del Río Cuarto y constituye una fuente de consulta para el análisis de la conformación y de las relaciones parentales de los grupos políticos. Carbonari también destaca el trabajo de recopilación documental y bibliográfica realizado por Víctor Barrionuevo Imposti y la publicación de una obra en tres tomos entre 1986 y 1988 que, bajo una perspectiva política y cronológica, constituye una referencia para los historiadores locales.

Por otra parte y en el marco de la renovación historiográfica de los años sesenta, se inscribe la perspectiva sociológica que inaugura José de Imaz. En los ochenta se destacan los trabajos de Adriana Fourcade, quien privilegió el enfoque cuantitativo para el análisis poblacional y productivo de la región. Las investigaciones refuerzan la noción de expansión de la frontera y de una población con rasgos igualitarios debido a la precariedad de la economía y de

\footnotetext{
2 Entre los diversos estudios que han abordado la problemática de la construcción de espacios políticos, el impacto del reformismo, la justicia y las milicias en diferentes áreas del virreinato rioplatense pueden mencionarse: Estruch, 2014; Barriera y Fradkin, 2016; Tío Vallejo, 2016; Polimene, 2011; Molina, 2016; Dainotto, 2018.
} 
los peligros de afrontaban. Para los años noventa Carbonari menciona los trabajos de Susana Gutiérrez, quien presenta un modelo explicativo de periodización en la ocupación del espacio. A fines de esa década los investigadores comenzaron a explorar las vinculaciones entre el espacio y las relaciones productivas y los temas privilegiados fueron la expansión agropecuaria, el mercado de tierras, la inmigración, entre otros (Carbonari, 2010: 1-23).

Este enfoque económico-social se complementa con nuevas discusiones epistemológicas que introdujeron las dicotomías entre lo macro y lo micro; la estructura y el sujeto; el poder y la resistencia; lo global y lo regional. Los trabajos de Carbonari y su equipo de investigación (1998, 2001-2002, 2004, 2009, 2011,2018 ) han abordado la historia de la región del río Cuarto durante la etapa colonial, el impacto de la revolución y la incidencia de los enfrentamientos posteriores a la independencia. El período colonial ha sido estudiado respecto del proceso de conquista y poblamiento de un espacio fronterizo, las características de la población hispano-criolla, las prácticas mercantiles de la región como nexo entre Buenos Aires, Cuyo y Chile, la importancia de las alianzas matrimoniales en la constitución de las familias de elite. Estas últimas incluían a los descendientes de los fundadores y a las familias de españoles que arribaron desde el siglo XVII.

Por otra parte, un trabajo de referencia para el área rural de la jurisdicción de Córdoba es el de Sonia Tell (2008) quien afirma que desde mediados del siglo XVIII la región atravesó un ciclo de incremento de sus exportaciones que se acentuó entre 1780 y 1810. La expansión se interrumpió con la revolución y la desestructuración del circuito minero andino. Los principales productos de exportación eran las mulas, los cueros vacunos y los textiles cuyos principales mercados eran el Alto Perú para las mulas, el ultramarino, vía el puerto de Buenos Aires, para los cueros y el Litoral, Buenos Aires y Paraguay para los textiles. En menor proporción se enviaban vacunos en pie a Chile y Potosí. Los retornos monetarios procedentes del comercio de mulas permitían saldar las importaciones de efectos de Castilla y otros artículos procedentes de Cuyo, Chile y Paraguay. Si bien la jurisdicción no era una importante receptora de migrantes, en las zonas fronterizas se detectan movimientos bastante fluidos de pobladores procedentes de provincias vecinas. El censo de 1778 le permite a la autora realizar un análisis comparativo de las unidades de producción e identifica que en la jurisdicción de Río Cuarto prevalecían unidades productivas independientes integradas por familias nucleares o extensas que no poseían esclavos pero tenían algunos agregados, generalmente emparentados con la familia nuclear. La producción del área era especialmente ganadera, cría de mulas, vacas y ovejas, con escasa agricultura y una intensa actividad mercantil a través del camino de postas. La zona era de 
poblamiento tardío y la cercanía con la frontera le otorgó características particulares y relaciones amistosas o conflictivas con los indígenas de acuerdo al período del que se trate (Tell, 2008: 82-83, 131-136 y 223-228).

Desde el punto de vista político Tell afirma que los efectos de las reformas borbónicas impactaron en mayor medida a partir de la creación de la gobernación intendencia y la llegada del primer gobernador intendente Rafael de Sobre Monte en 1785, quien concentró gran parte de las funciones que había desempeñado hasta ese momento el cabildo de la ciudad de Córdoba (Tell, 2008: 359-407). En términos de Ana Inés Punta (1997, 2001, 2011) la frontera pasó a ser un problema de la gobernación que pretendía centralizar y articular las políticas con relación a la población hispano-criolla así como estabilizar las relaciones con las distintas parcialidades indígenas. Los cabildos y los comandantes de frontera debían responder a la autoridad del gobernador intendente. Los conflictos de jurisdicción, tema central de este artículo, fueron frecuentes en un contexto de militarización de la frontera (Punta, 2011: 187-202).

Sobre las relaciones interétnicas es importante remitir a los trabajos de Marcela Tamagnini y Graciana Pérez Zavala (2010). Respecto del período tardocolonial Olmedo, Tamagnini, Lodeserto $(2011,2019)$ interpretan las políticas borbónicas en el marco de conflictos inter-imperiales y en procesos militares de fortalecimiento de la vigilancia, el control y la defensa de las fronteras del imperio. En coincidencia con lo afirmado por Punta, consignan que la militarización reforzó el poder de los comandantes lo cual generó disputas con los cabildos locales. Acuerdan con otros autores en que fue particularmente Sobre Monte quien hizo efectiva esa acción a partir de la construcción de fuertes intermedios y pequeños núcleos urbanos hacia los que fue trasladada compulsivamente la población. Asimismo la paz con los indígenas permitía garantizar la seguridad de los núcleos de población y la circulación de mercancías. Según los autores el plan de Sobre Monte no se agotó en la instalación de los fuertes y fortines. En su condición de virrey se interesó en el adelantamiento de la frontera hasta el río Quinto para lo cual promovió la exploración de la zona (Tamagnini, Olmedo y Lodeserto, 2011: 93-114 y Olmedo y Tamagnini, 2019: 36-72).

Menos documentada historiográficamente está La Carlota, para la que se cuentan los trabajos del historiador local Alberto Abecasis (2017) quien ha recopilado documentos, escrito libros y artículos de divulgación. Por su parte, Elizabeth Rustan (2003) ha analizado las características sociodemográficas de la población de la villa a través de los padrones de 1789 y 1796. A través de los datos proporcionados la autora incluye una serie de información cuantitativa respecto de las categorías socio-étnicas, edades, sexo, características de las unidades censales, índice de masculinidad y condición de agregatura. Rustan (2010) también estudió el impacto de la administración borbónica en la región a 
partir de los tratados diplomáticos con las poblaciones originarias. El reformismo buscaba pacificar las diputas entre parcialidades indígenas a los efectos de evitar la inestabilidad en la frontera. En este sentido la autora presenta a los pueblos autóctonos como sujetos activos con una importante capacidad de negociación (Rustan, 2010: 17-38).

En el marco de la militarización promovida por las políticas borbónicas y sobre la problemática jurisdiccional Elizabeth Rustan (2011) ha analizado algunos episodios de disputas en la frontera sur de la gobernación intendencia de Córdoba. Precisamente a fines de la década de 1790 en la villa de La Carlota se produjeron tensiones entre el comandante general de la frontera de Córdoba Simón de Gorordo y los miembros del cabildo recientemente instalado. El trabajo evidencia que, aun frente a episodios en apariencia menores, las disputas entre autoridades civiles y militares resultaban frecuentes en el nuevo marco del reformismo (Rustan, 2011: 139-155).

Los antecedentes historiográficos expuestos permiten enmarcar la problemática del artículo e insertar el análisis en fenómenos comunes que afectaban a las áreas marginales del imperio español en un contexto reformista que intentaba revertir la situación de crisis que afectaba las relaciones imperiales.

\section{Nuevas jurisdicciones en espacios fronterizos}

António Hespanha (1989) considera que en la concepción tradicional o medieval del poder la patrimonialización del espacio político implicaba que, una vez que se atribuían a un señor o a una comunidad poderes políticos sobre una zona, estos se incorporaban al patrimonio de su titular y se consideraba su indisponibilidad para cualquier otro poder político. Incluso cuando existía superioridad jurisdiccional, el rey por ejemplo, este ejercía un poder de control y armonización pero no en base a un lazo de subordinación o jerarquía. Los dominios jurisdiccionales de los poderes inferiores mantenían una expresión político-territorial autónoma (Hespanha, 1989: 81-85).

Esta lógica de comprender y ejercer el poder tuvo una larga vigencia en la América hispana y su persistencia confrontó, como se verá más adelante, con las políticas borbónicas. Asimismo, en una instancia posterior, las tradiciones de autonomía entraron en tensión con los diferentes proyectos de centralización estatal durante la etapa postrevolucionaria. ${ }^{3}$

\footnotetext{
${ }^{3}$ Resulta pertinente para el presente análisis la afirmación de Alejandro Agüero quien retoma a Hespanha para explicar la relación entre jurisdicción y territorio durante el antiguo régimen según dos estrategias: una tradicional caracterizada por la miniaturización del espacio en pequeñas comunidades y la patrimonialización del poder sobre el territorio. En este sentido el espacio político constituía un bloque con la comunidad y sus tradiciones. La segunda estrategia,
} 
Durante el siglo XVIII el reformismo borbónico introdujo un proceso de reterritorialización materializado a través de diferentes disposiciones entre las que se cuenta la "Real Ordenanza de Intendentes para el establecimiento é instruccion de intendentes de exército y provincia en el virreinato de BuenosAires", establecida por el rey Carlos III en 1782. ${ }^{4}$ De acuerdo con la ordenanza el Virreinato del Río de La Plata se dividió en ocho intendencias y cuatro gobiernos subordinados: Intendencias de Buenos Aires, del Paraguay, de Córdoba del Tucumán, de Salta del Tucumán, de Potosí, de Cochabamba, de la Paz y de Charcas. Los gobiernos subordinados eran: Moxos, Chiquitos, Montevideo y Misiones. En este marco se definió la separación de la Gobernación del Tucumán en dos jurisdicciones: Córdoba del Tucumán y Salta del Tucumán. En la frontera sur de la actual provincia de Córdoba se constituyeron tres fuertes principales: Punta del Sauce (1752), Santa Catalina (1778), Las Tunas (1779) y varios fortines intermedios, entre los que se cuenta el de Concepción (1782) instalado sobre una antigua capilla consagrada a la Inmaculada Concepción de la Virgen María. Esta jerarquización obedecía a criterios geográficos y militares enmarcados en la política implementada en la frontera sur del imperio. ${ }^{5}$

Según el planteo de María Rosa Carbonari los primeros españoles en arribar a la región del río Cuarto, límite entre las sierras y el llano, lo hicieron en el mismo año de la fundación de la ciudad de Córdoba en 1573 (Carbonari, 2011: 23-43). Las tierras pasaron a pertenecer a los descendientes del fundador Jerónimo Luis de Cabrera y a comienzos del siglo XVIII uno de los herederos fraccionó la propiedad. Esta parcelación posibilitó el arribo de nuevos pobladores que se agruparon alrededor de la antigua capilla del casco de una

doctrinal, se orientaba por criterios de legitimación carismática y luego racional de centralización y unificación del territorio (Agüero, 2018: 441-480). Por su parte Sábato y Ternavasio consideran que en América hispana, ante la acefalía monárquica, prevaleció el carácter territorial de los cuerpos intermedios. Ello derivaba del carácter compuesto o plural de la monarquía en reinos, provincias, ciudades (Sábato y Ternavasio, 2015: 237-272). La crisis de acefalía y sus implicancias así como los lenguajes y las prácticas políticas han sido analizadas por diferentes autores (Annino, 2015: 37-52; Guerra, 1998: 109-139).

${ }_{4}^{4}$ Real ordenanza para el establecimiento é instruccion de intendentes de exército y provincia en el virreinato de Buenos-Aires: año de 1782.

${ }_{5}$ Para el mundo hispanoamericano Darío Barriera refiere al territorio como el resultado de relaciones históricas de carácter político entre una sociedad, el terreno que organiza y las instituciones ordenadoras. Una vez producida la conquista resultó prioritario establecer circuitos de comunicación que permitieran mantener el flujo de los intercambios que fuesen convenientes para Castilla. Se crearon gobernaciones con sus respectivas cabeceras, se instalaron pueblos, villas, lugares y pagos. Las ciudades constituyeron entidades fundamentales que agregaban o desagregaban jurisdicciones $\mathrm{y}$, de este modo, se generaban los espacios políticos que se podían constituir en ámbitos de confrontación y de conflicto, en núcleos organizadores de pautas identitarias y, por ende, creadores de alteridades (Barriera, 2012: 5384). 
de las estancias donde posteriormente se localizó el fuerte de la Concepción a cargo del comandante Juan Agustín de Balmaceda y que más tarde adquirió el rango de villa (Barrionuevo Imposti, 1986: 51-71).

Por disposición del virrey Vértiz de abril de 1780 se procedió a reforzar la frontera sur a los efectos de proteger el traslado de mercancías desde Buenos Aires hacia el interior y hacia Chile. En 1785 el Marqués Rafael de Sobre Monte, quien se desempeñaba como gobernador intendente de Córdoba del Tucumán, realizó una visita a la jurisdicción de la intendencia y elevó un informe detallado al virrey Loreto. Al año siguiente encomendó la formación del pueblo de la Concepción a Alberto de Soria y la distribución de las tierras al comandante Ventura Echeverría. A la jurisdicción se agregaron los poblados y fuertes de Santa Catalina, San Fernando y San Bernardo. Asimismo se incorporaron los pueblos y lugares de: La Reducción, La Esquina, El Tambo, las Lajas, La Cruz, Tegua y La Tapa. En 1793 Concepción contaba con sesenta y ocho familias y en 1797 con un poblamiento de cuatrocientos cincuenta y dos personas (Torre Revello, 1946: 47-48).

\section{Mapa 1}

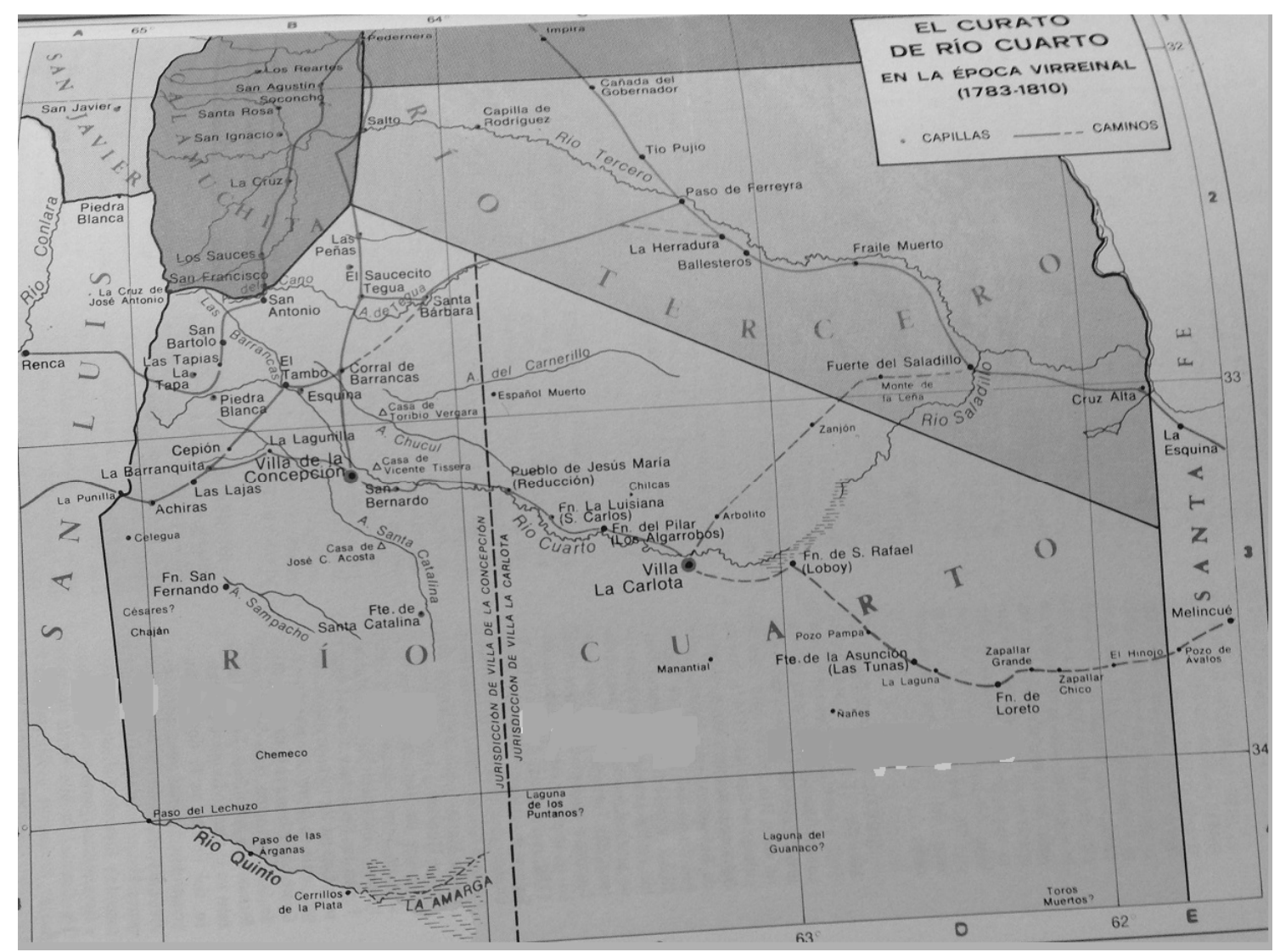

Fuente: Barrionuevo Imposti, Víctor (1986: 77). 
Sobre Monte ordenó la distribución de terrenos conforme al trazado del pueblo de la Concepción (fundado el 11 de noviembre de 1786) en momentos en que se desempeñaba como gobernador intendente de Córdoba del Tucumán. El poblado fue ratificado con categoría de villa real por cédula emitida por Carlos IV en Aranjuez en abril de 1797. 6 Se ordenó la erección del ayuntamiento con un alcalde ordinario, cuatro regidores, un alguacil, un mayordomo y un escribano. También bajo el gobierno de Sobre Monte el fuerte Punta de Sauce, donde residía la comandancia general de frontera, adquirió jerarquía de villa con el nombre de Villa Real de La Carlota y desde 1798 funcionó la institución capitular. En este pueblo se relevaron setenta y seis familias en 1793. Si bien ambos poblados contaban con cabildo solo se conservan las actas correspondientes a la Villa de la Concepción que corresponden al período 1798$1812 .^{7}$

Según el sistema defensivo propuesto por Sobre Monte, en La Carlota residiría la comandancia general de la frontera del sur cuyo titular sería designado por el propio gobernador intendente (Barrionuevo Imposti, 1986: 101-102). La decisión de Sobre Monte de ubicar la comandancia en La Carlota se debía a que constituía el centro geográfico de la frontera. Como se verá, este será uno de los puntos de conflicto entre ambos poblados dado que el cabildo de Concepción pretendía que se produjera el traslado de la comandancia a esa villa. Entre los argumentos se sostenía la necesidad de hombres para la defensa de Concepción, la situación "poco ventajosa por lo escaso de población" de La Carlota y la condición de su fuerte que se encontraba derruido. ${ }^{8} \mathrm{La}$ representación del procurador y la exposición de los miembros del cabildo serían remitidas al gobernador intendente para su resolución. Sin embargo la sede de la comandancia no fue trasladada.

El acta de fundación del pueblo de la Concepción del Río Cuarto justifica ampliamente la necesidad de su instalación bajo el argumento de los perjuicios que causaba la "dispersión" de población en los fuertes, parroquias y capillas rurales. El único "remedio oportuno de evitar los males que son consiguientes a la falta de educación y policía" era la promoción de fundación de pueblos en los que se reuniesen las familias dispersas brindándoles "terrenos despoblados útiles para la agricultura". Asimismo se evitarían los "perjuicios por las repetidas invasiones" de los "indios infieles". Estas apreciaciones se reiteraban con motivo del proceso de donación de terrenos en febrero de 1794. En ese momento, bajo escribano público, se adjudicaron tierras a varios pobladores y

\footnotetext{
${ }^{6}$ Academia Nacional de la Historia, Actas capitulares (1947: 421-426).

${ }^{7}$ La edición de las actas capitulares de la Villa de la Concepción del Río Cuarto del período 1798-1812 fue realizada por la Academia Nacional de la Historia e incluye otros documentos entre los que se encuentra el acta de fundación. Las actas del cabildo de la Carlota no fueron editadas, tampoco se han localizado los documentos originales.

${ }^{8}$ Academia Nacional de la Historia, Actas capitulares (1947: 318-320).
} 
se justificaba la acción en virtud del proyecto de Sobre Monte de poner a reparo "esta frontera destruida y aniquilada por el infiel bárbaro enemigo pampa". ${ }^{9} \mathrm{De}$ este modo se justificaba una nueva avanzada imperial sobre áreas consideradas, hasta ese momento, marginales.

Tomar efectiva posesión del territorio implicaba fundar pueblos, villas y ciudades, proceso que en áreas de frontera requería el establecimiento de fortines y fuertes principales. La jerarquía de villa que adquirieron los poblados y la institución de los cabildos no implicaron la posibilidad de efectivizar las reuniones en los tiempos acordados. En muchos casos las ausencias se debían a la necesidad de los funcionarios de atender sus propiedades fuera del casco urbano. ${ }^{10} \mathrm{El}$ acta de fundación establecía que a los vecinos más antiguos (un total de veintidós) se les otorgarían sitios frente a la plaza, "exceptuando dos pertenencias a la parte del norte para la Iglesia y casas del Ayuntamiento". ${ }^{11}$

Desde las primeras reuniones del cabildo de Concepción uno de los tópicos prevalecientes fue la organización de las contribuciones de los pobladores ya sea en dinero, terrenos, animales o en servicio personal. A pesar de las sucesivas disposiciones del cuerpo capitular, muchos terrenos quedaban sin trabajar y no se hacían efectivas las debidas construcciones en los solares adjudicados a tal efecto. Las tensiones también se evidenciaban con las demoras que se produjeron en torno a las mejoras que se solicitaban realizar sobre los terrenos adjudicados ya que su apropiación en la jurisdicción de la villa se efectivizaba con el necesario cercado y construcción de edificios. Esta acción no siempre se concretaba por lo cual el cabildo dispuso, en mayo de 1802, que se verificara la instalación de cercados y viviendas bajo pena de conceder los terrenos a quienes pudieran hacerlo y, de este modo, "aumentar el número de vecindario". En sucesivas reuniones se reiteraba el reclamo a los pobladores para que cercaran y construyeran viviendas sobre los predios otorgados de modo de evitar la especulación con su eventual venta. ${ }^{12}$

Otro punto de conflicto refiere al suministro de carne. La escasez de abastecimiento de manera voluntaria impulsó al cabildo a tomar medidas para obligar al vecindario que poseía suficiente ganado a proveer de carne a la villa. El acuerdo del 24 de septiembre de 1802 incluyó la lista de los hombres y mujeres que estarían obligados a trasladar y vender la carne semanalmente en la plaza bajo pena de doce pesos de multa a quien incumpliese con esa obligación. Otro tanto se disponía para el aprovisionamiento de pan: “todas las

\footnotetext{
9 Academia Nacional de la Historia, Actas capitulares (1947: 429).

10 Similar situación se advierte para el caso del cabildo de la ciudad de Córdoba donde los vecinos justificaban sus reiteradas ausencias a las reuniones por encontrarse dedicados a la cría de mulas en sus haciendas (Punta, 2001: 242).

${ }^{11}$ Academia Nacional de la Historia, Actas capitulares (1947: 421-422).

${ }^{12}$ Academia Nacional de la Historia, Actas capitulares (1947: 248-249).
} 
amansadoras traigan a vender el pan, y otros cualesquiera comestibles de harina [...] poniéndose a venderlo en una de las esquinas de la plaza" ${ }^{13}$

Como puede advertirse el origen de las villas se caracterizó por un alto grado de precariedad económica y administrativa. La puesta en funcionamiento de estos nuevos espacios políticos no estuvo exenta de tensiones y conflictos que habilitan la posibilidad de analizar la dinámica en la que se insertaban los diferentes actores sociales, tanto individuales como colectivos, sus ámbitos de confrontación y las estrategias de negociación al interior o exterior de las facciones en pugna. Aun cuando se trataba de nuevos espacios jurisdiccionales las tradiciones de la cultura política se mantuvieron frente a las imposiciones del reformismo de los Borbones.

\section{La construcción de espacios políticos y la emergencia de tensiones jurisdiccionales}

El proceso de equipamiento político del espacio físico en Hispanoamérica no estuvo exento de conflictos inherentes a las disputas y competencias jurisdiccionales que derivaban de la propia estructura administrativa que la corona había diseñado. En este sentido conviene remitir a las discusiones que retoma António Hespanha (1993) en relación a que el espacio, en tanto construcción histórica, ha sido revisada por los geógrafos quienes ya no lo consideran como una entidad fija y objetiva sino que forma un bloque con las comunidades humanas. La noción de espacio se considera bajo el signo del pluralismo por su triple carácter de construido, simbólico y heterogéneo. Una vez investido de sentido, el espacio se convierte en una realidad significante y la división política constituye un instrumento de poder. El autor portugués define al territorio como aquel espacio equipado desde el punto de vista político y administrativo, producto de una serie de prácticas culturales y simbólicas. La territorialización no implica necesariamente integración física porque el espacio jurisdiccional no siempre constituye un continuo geográfico. Sobre el mismo espacio pueden ejercerse diversos poderes pertenecientes a diferentes jerarquías (Hespanha, 1993: 85-121).

En el área de estudio del presente trabajo las disputas emergían cuando ocurrían episodios que se advertían como amenazas para la integridad territorial de los espacios políticos que formaban parte de la jurisdicción de las villas pero que se integraban a poderes más amplios, por ejemplo de la órbita de la comandancia militar. Un momento de tensión se produjo cuando, tras la reconquista de la ciudad de Buenos Aires en agosto de 1806, la tropa y los oficiales ingleses prisioneros fueron destinados a diversos puntos del interior: cuatrocientos a Córdoba, doscientos a Mendoza, doscientos a San Juan, cien a

${ }^{13}$ Academia Nacional de la Historia, Actas capitulares (1947: 141-142). 
Santiago del Estero y cien a San Luis. Respecto de los destinados a Córdoba, algunos fueron alojados en casas particulares, otros enviados a Alta Gracia, a otras ex estancias jesuíticas y un grupo fue remitido a La Carlota. Permanecieron aproximadamente durante diez meses y en julio de 1807 fueron trasladados a Buenos Aires para embarcarlos de regreso a Europa.

De acuerdo a los datos que brinda el padre jesuita Pedro Grenon en noviembre de 1806 se custodiaban en La Carlota cincuenta y dos prisioneros ingleses para quienes se habían destinado veintiséis guardias. En ese lapso se produjo un episodio entre el alcalde de la villa José Benito de Lago y el comandante de frontera Juan de Altolaguirre. El hecho daba cuenta de los conflictos políticos locales y se inscribe en la generalidad de la situación que se presentaba con los prisioneros británicos luego de la victoria porteña sobre la primera invasión en 1806.

El 14 de marzo de 1807 el alcalde Lago envió un oficio al comandante de frontera por el cual solicitaba que se distribuyeran los prisioneros ingleses en otros poblados debido al riesgo de sedición o motines que implicaban para la villa. La solicitud se realizaba con acuerdo del cuerpo capitular y se argumentaba que la "guarnición" estaba avocada a la acción contra los indígenas. A la debilidad de la custodia se sumaba, según el alcalde, la precariedad del refugio y la posibilidad de fuga en virtud de que recibían noticias de los "progresos de sus paisanos en la otra Banda" (Uruguay). El alcalde responsabilizaba y prevenía al comandante acerca de la peligrosidad de fuga de un "enemigo, perverso por su herejía, de la Iglesia Católica y por su codicia de las vidas y caudales de los españoles" (Grenon, 1929:123-124).

Altolaguirre respondió, con fecha 16 de marzo, que no existía motivo para distribuir los prisioneros dado que se trataba de cincuenta hombres desarmados y subordinados a setenta soldados armados a los que se sumarían diez o doce que reemplazarían a los desertores. Agregaba que se los mantenía fuera del barracón durante el día para evitar la propagación de enfermedades y por la noche permanecían custodiados por catorce hombres. Por otra parte advertía sobre las dificultades para distribuir cincuenta prisioneros en los fuertes de la frontera donde no existían cuarteles apropiados ni recursos para alimentarlos. El comandante aducía que no había recibido reclamos por parte del cabildo de La Carlota para efectuar el traslado y que tampoco solicitaría el permiso a los jefes dado que se arriesgaba a recibir una "severa reprensión". Finalmente advertía al alcalde que evitara las prevenciones referidas a los "asuntos que son privativos de esta Comandancia; porque además de estar fuera del orden de la buena política, sirve para alterar la buena armonía que debe haber entre las dos jurisdicciones" (Grenon, 1929:125-126).

El alcalde Lago replicó que, si bien reconocía que la comandancia no podía apartarse de las órdenes que había recibido, su propuesta de traslado 
debía ser refrendada por la autoridad competente. En segundo lugar exponía sus dudas acerca de la efectividad de la guardia porque "las deserciones y el ningún brillo" de los soldados quedaban demostrados. A continuación también rebatía el argumento del comandante sobre la carencia de suministros en otros parajes y reiteraba la responsabilidad del jefe militar con relación a la posibilidad de excesos que pudieran cometer los prisioneros (Grenon, 1929: 127129).

El intercambio entre ambas autoridades continuó en términos de las responsabilidades que les competían y la superioridad que cada uno esgrimía con referencia al estado de la guarnición, al armamento y a la seguridad del vecindario. El alcalde observaba que las obligaciones militares que se imponían a los vecinos les impedían atender adecuadamente sus trabajos en las haciendas. El 20 de marzo Altolaguirre intimó a Lago para que se abstuviera de enviar "más Papeles sobre este particular, y ocurrir con mis Oficios al Tribunal que le convenga [...] en donde después de determinar sobre el punto principal nos darán a cada uno el lugar que nos corresponda" (Grenon, 1929: 130-131).

El comandante de La Carlota remitió al gobernador los oficios intercambiados, con fecha 24 de abril por intermedio del comandante de armas Santiago de Allende, quien tomó partido por Altolaguirre al expresar su opinión de que el funcionario capitular "se ha abocado y entremetido en asuntos que no le son peculiares y en términos de alterar la buena armonía que es tan necesaria en ambas jurisdicciones". Por su parte el alcalde se dirigió al gobernador para acusar al comandante de frontera de disponer de los vecinos "para la ocupación de las armas, impidiendo a muchos con el entretenimiento militar el importante cuidado y manejo de las propias haciendas", además de propasarse con su lenguaje "ofensivo hacia la autoridad ordinaria” (Grenon, 1929: 132).

El gobernador intendente Victorino Rodríguez ordenó que el expediente pasara al funcionario de la Real Hacienda Domingo Deheza quien prevenía al alcalde acerca de que "en casos de esta naturaleza, omita en sus dictámenes las voces de exhorto y requiero; y también otras equivalentes que indiquen alguna jurisdicción hacia los Comandantes Militares" (Grenon, 1929: 133). Agregaba Deheza que en lo referido a los prisioneros ingleses dirigiera sus reclamos a la gobernación o a la comandancia general de provincia.

De acuerdo con este dictamen el gobernador emitió su fallo con fecha 11 de mayo de 1807. En el mismo declaraba que, frente a la solicitud del alcalde sobre la distribución de prisioneros ingleses, no advertía causa para hacerlo a menos que algún caso extraordinario lo ameritara. La representación debía hacerse frente a los respectivos jefes provinciales. Asimismo llamaba la atención por su introducción en jurisdicción ajena con "expresiones imperiosas" (Grenon, 1929: 134). 
Al episodio de La Carlota se suma otro conflicto que dio inicio a un expediente en la ciudad de Córdoba por una eventual conspiración de prisioneros que también manifiesta el temor que suscitaba en las autoridades civiles la presencia inglesa, las disputas sobre la administración de los detenidos y las relaciones de competencia entre las autoridades.

Virginia Ramos (2017) analizó el impacto que produjo en la ciudad de Córdoba la presencia de los prisioneros y las diferentes reacciones que se generaron en las autoridades locales. La autora focaliza su estudio en los conflictos entre la facción sobremontista, que había acaparado las funciones capitulares durante la gobernación del propio marqués de Sobre Monte, y la de los partidarios de Ambrosio Funes que fue elegido alcalde de primer voto en 1807. El enfrentamiento faccioso databa de fines del siglo XVIII y la presencia de los ingleses constituyó un episodio más dentro de las rivalidades preexistentes.

Ambrosio y Gregorio Funes y sus partidarios confrontaban con el gobernador intendente Victorino Rodríguez y el comandante de armas Santiago Allende respecto del posicionamiento que las autoridades debían adoptar frente a los ingleses. Ambrosio Funes insistía en que los reclusos gozaban de amplias libertades, al tiempo que tanto el gobernador como el comandante justificaban su postura respecto del trato que los prisioneros recibían. La inquietud de los miembros del cabildo estaba centrada en la posibilidad de que los ingleses pudiesen comprar armas. El tema llegó a la Real Audiencia que encargó al gobernador y al comandante extremar la vigilancia, separar a los soldados de los oficiales y prohibir a los prisioneros que mantuvieran trato con los vecinos (Ramos, 2017: 7-9).

Ramos refiere a una supuesta sublevación de prisioneros ingleses que no fue comprobada pero que consta en el expediente mencionado anteriormente y que incluye las declaraciones de los testigos y los respectivos informes que elevaron las diferentes autoridades intervinientes: el cabildo, la Real Audiencia, el gobernador intendente y el comandante de armas (Ramos, 2017: 14-15).

El faccionalismo que caracterizaba a la política local cordobesa se puso de manifiesto a través de las sucesivas reuniones del cabildo de Córdoba durante los meses de junio y julio de 1807 en las que se refería a la presencia de los prisioneros ingleses. Con fecha 2 de junio de 1807 el cabildo exponía sobre los "repetidos clamores del Pueblo" en vistas del aumento de los "prisioneros enemigos del estado y de la Religión", de lo cual se derivaban numerosos "inconvenientes", para lo cual solicitaban que se informara al gobierno y a la Real Audiencia a fin de que "se apliquen los remedios más convenientes" dada la carencia de "seguridad" para el vecindario. ${ }^{14}$

${ }^{14}$ Archivo Municipal de Córdoba, Actas Capitulares (1969: 270-271). 
El cuerpo capitular insistió en el tratamiento del tema debido a que la "conspiración premeditada" requería que se adoptaran los recaudos pertinentes a fin de "impedir tan pérfidos proyectos". En consonancia con esta situación el cabildo propuso al gobernador un conjunto de medidas: en primer lugar que se levantara un cuerpo de milicianos urbanos al mando del comandante de armas para custodia del "Pueblo". En segundo término solicitaba que se aceptara la oferta de los vecinos para costear la custodia de los prisioneros que se trasladaran a La Rioja. Como tercer punto proponía el aumento del número de prisioneros que debían salir de la ciudad de Córdoba a fin de evitar "imponderables males". El cuarto ítem solicitaba que se evitara que los prisioneros "anden por las calles con pretexto alguno". Finalmente se requería que se pasara "orden pública" para que el "pueblo se precava contra alguna sorpresa de dichos enemigos" $y$, a tal fin, se armen "del modo permitido para su defensa". ${ }^{15}$

Ante la noticia del nuevo triunfo sobre las armas británicas, el 24 de julio de 1807 el cabildo tomó conocimiento de las órdenes devenidas de Buenos Aires respecto del regreso de los prisioneros a la capital virreinal. En agosto de 1807 los reclusos fueron remitidos a la ciudad portuaria y embarcados hacia su lugar de origen. Finalmente en sesión del 31 de julio se hacía referencia al expediente formado sobre la conjuración de prisioneros ingleses en el que habían tenido participación tanto el cabildo como la gobernación y que, según el ayuntamiento, había quedado justificada a pesar "del empeño que se ha puesto en ocultarlo, como lo ha informado este Ayuntamiento a la Superioridad". ${ }^{16}$

Los sucesos de La Carlota y Córdoba evidencian conflictos que enfrentaban a las autoridades y sus partidarios al tiempo que se configuraban lealtades $y$ enfrentamientos personales que pueden interpretarse como comportamientos facciosos y como el emergente de la competencia entre autoridades civiles y militares en el contexto de afianzamiento de estas últimas como consecuencia de la política borbónica. La disputa entre el alcalde y el comandante de la villa constituye la manifestación del proceso de construcción de espacios políticos en territorios de frontera dotados de un aparato político y militar en los que, en términos de Carlos Garriga, se fortalecían las plazas militares en detrimento de la tradición de autogobierno que caracterizaba a las ciudades coloniales. ${ }^{17}$

\footnotetext{
${ }^{15}$ Archivo Municipal de Córdoba, Actas Capitulares (1969: 277-279).

${ }^{16}$ Archivo Municipal de Córdoba, Actas Capitulares (1969: 297).

${ }^{17} \mathrm{El}$ autor identifica una dicotomía en la consideración del estatus del espacio político. Por una parte la condición de América como parte esencial de la monarquía y, por lo tanto, capacitada para el autogobierno y, por otra, como colonia sometida a la metrópoli europea. La primera condición permite hablar de "patrias criollas" y la segunda alcanzó su mayor expresión con la instalación de "plazas militares" durante el reinado de Carlos IV quien gobernó entre 1788 y 1808. La estrategia de instalación de plazas militares debió reforzar la construcción de patrias
} 
La presencia de los prisioneros ingleses, que se percibía como amenaza a la tranquilidad pública, activó la emergencia de rivalidades locales. Las tensiones y su resolución habilitaban el afianzamiento de algún grupo/facción civil/militar. Más allá de que la amenaza inglesa, portuguesa o francesa se advertían como amenazas a escala imperial, se impone la pregunta referida a si los prisioneros ingleses se percibían como un verdadero peligro a nivel local o su presencia solo constituía un pretexto para interpelar a la facción opuesta y dirimir conflictos de más largo aliento. En Córdoba, por ejemplo, no se comprobó la conspiración aludida por el cabildo y al momento de remitir los prisioneros para ser reembarcados a Europa varios ingleses solicitaron permanecer en la ciudad, requerimiento que fue atendido.

Esta cuestión se vincula a la discusión historiográfica sobre el grado de efectividad que tuvieron las reformas borbónicas en el plazo inmediato. La tradición de autogobierno del que habían gozado las ciudades y villas coloniales actuaría como contención frente al fortalecimiento del poder real que pretendían las nuevas medidas. El reformismo borbónico, según Garriga, tuvo el carácter de un absolutismo negociador en búsqueda de consensos. Frente a una monarquía jurisdiccional se impuso una administrativa con alto contenido de militarización del aparato de gobierno. ${ }^{18}$ La necesidad de potenciar la presencia de las milicias se fundaba en los requerimientos de la defensa interior y exterior y este proceso no estuvo exento de la negociación con las elites criollas. La instalación de plazas militares debía servir a los fines estratégicos de

criollas. La crisis de acefalía demuestra la presencia de los dos modelos. Con el juntismo se generaron poderes territoriales imaginados por el patriotismo criollo que, en definitiva, estaban fundados en los autonomismos americanos (Garriga, 2009: 1-70). Por su parte y sobre el espacio político en Hispanoamérica Pérez Vejo señala que la oposición entre dos formas de entender la identidad: la territorial y la genealógica cristalizó en la identificación que los teóricos han realizado de dos modelos diferentes de nación: por una parte el cívico, basado en la voluntad de los individuos, con carácter territorial y, en segundo término, el étnico-cultural, consecuencia de diferencias consideradas naturales y de carácter genealógico. Propone dilucidar la dialéctica entre lo genealógico (la nación) y lo territorial (la patria). Con los movimientos juntistas el sujeto de soberanía eran las ciudades y esto tiene un contenido territorial y no nacional. El componente identitario en términos de una comunidad con rasgos culturales propios es inexistente en la Hispanoamérica de las primeras décadas del siglo XIX (Pérez Vejo, 2015: 171204).

${ }^{18}$ Sobre los procesos de centralización política resulta interesante la propuesta de Hespanha de revisar supuestos historiográficos que postulan la neutralidad, despolitización y docilidad de la administración. Para el autor portugués la administración constituye un factor autónomo del sistema político, sin embargo en la historiografía ha sido frecuente sobreestimar el poder de la corona sin tener en cuenta sus posibilidades de hacer efectiva su potestad a través del sistema administrativo (Hespanha, 1989: 36-37). 
la corona en un contexto de fuerte patrimonialización en la gestión de los dominios coloniales. ${ }^{19}$

El carácter militarista y administrativo de la política borbónica confrontaba con la escasez de recursos, habitantes y aislamiento aducidos por los habitantes de los poblados de la frontera sur de Córdoba. Esta insuficiencia constituía un tópico recurrente al que los vecinos aludían cuando reiteraban sus quejas ante el cabildo y generaban tensiones y disputas entre las autoridades. A ello se añadían las dificultades para el reclutamiento y sostenimiento de los destacamentos militares.

En enero de 1806 el cabildo de Concepción se reunió para tratar una orden del comandante general de frontera por la cual solicitaba que se remitieran soldados hacia los destacamentos en Santa Catalina y La Carlota. La respuesta del cuerpo capitular fue que no se alistaran, reclutaran o formaran levas en aquellos territorios de frontera, cuyo único amparo frente a la "amenaza" indígena eran los hombres. ${ }^{20} \mathrm{El}$ mismo argumento de escasez de población se esgrimió al momento de recibir un pliego del virrey en el que requería auxilios de milicianos y caballos para socorrer a Buenos Aires frente a la primera invasión inglesa en 1806. Si bien el cabildo informó a los vecinos sobre la solicitud, se acordó sobre la conveniencia de elevar un informe al gobernador intendente acerca del "desamparo en que se hallaba esta villa de gente" y la necesidad de "guarecer la frontera". Por lo tanto la posibilidad de enviar auxilios a la capital virreinal quedaba muy reducida. ${ }^{21}$ En ambos casos el cuerpo capitular desoía los requerimientos de autoridades de mayor jerarquía. Si, como consigna Rustan (2010), las tensiones en la frontera no fueron permanentes y la administración borbónica encontró limitaciones para implementar sus políticas militares es posible inferir que la renuencia del cabildo para efectuar levas puede interpretarse como un acto de rebeldía ante las órdenes superiores más que una verdadera necesidad de resguardo militar.

En el marco de las relaciones de frontera, la competencia entre las autoridades se evidenció nuevamente con motivo del conflicto que involucró al comandante Juan de Altolaguirre, el mismo que había confrontado con el alcalde de La Carlota con motivo de la presencia de los ingleses. El acta capitular del 1 de febrero de 1808 refiere a la lectura de un oficio del gobernador intendente Gutiérrez de la Concha acerca de una representación que le había dirigido el comandante Altolaguirre "alusiva a la arbitrariedad con que había

\footnotetext{
${ }^{19}$ La creación de la Junta de Fortificaciones de Defensa de Indias era la expresión máxima de esa política. Se trataba de una junta de expertos compuesta de militares de alto rango que habían tenido alguna experiencia en temas americanos. Si bien tenía carácter consultivo, la Junta ejerció un alto grado de influencia en la política colonial (Garriga, 2019: 56).

${ }^{20}$ Academia Nacional de la Historia, Actas capitulares (1947: 178-180).

${ }^{21}$ Academia Nacional de la Historia, Actas capitulares (1947: 202).
} 
librado el Alcalde Ordinario de esta villa" el pase del cacique Chacalen e "indios de su comitiva". El gobernador prevenía al alcalde de la villa de la Concepción para que se "abstenga de franquear semejantes licencias" en vistas de que eran facultad "privativa" del comandante de frontera. El gobierno tomaría las "providencias" eficaces para "reprender y contener desórdenes" y comunicaba a los cabildos de Concepción y de La Carlota que autorizaba al comandante a actuar según "lo pidan las circunstancias de los lances que puedan ocurrir". De este modo el gobernador intendente sostenía las prerrogativas de la autoridad militar y desautorizaba posibles decisiones que pudieran adoptar los cuerpos capitulares. $^{22}$

Otro episodio se desarrolló a partir de octubre de 1808 en que Antonio Bricio Arias se presentó como capitán de milicias urbanas "de esta villa del Río Cuarto" ante el gobernador y denunció al alcalde José Giráldez porque había contravenido las medidas relacionadas con el pago que debía realizarse a los soldados milicianos que estaban obligados a hacer guardia en las cárceles. Conviene aclarar que Arias se desempeñaba también como procurador de cabildo, cargo que lo habilitaba para realizar las representaciones legales ante las autoridades superiores como el gobernador, la audiencia o el virrey.

Ante la solicitud de Arias el gobernador intendente Gutiérrez de la Concha respondió con el envío de una orden en consonancia con lo dispuesto oportunamente por el virrey Marqués de Avilés respecto de esas obligaciones de pago. El decreto fue remitido al capitán Arias quien expresó que, pese a lo resuelto por el gobernador, el alcalde "continuaba a su propia autoridad ocupando a los milicianos urbanos de mi compañía en las guardias de la cárcel". Frente a esta desobediencia el comandante instruyó a los cabos para que no prestaran los auxilios a menos que fuesen pagos. La reacción del alcalde no se hizo esperar y se presentó frente al comandante "muy alterado" por no haber recibido la asistencia militar correspondiente. Arias respondió que el auxilio "estaba pronto" siempre y cuando se efectuara la paga según "lo había dispuesto el Señor Gobernador". El alcalde insistió en que todos los vecinos de la villa estaban obligados a hacer guardia. Esta respuesta fue interpretada por el comandante como una amenaza y abuso de autoridad "apropiándose de facultades militares". ${ }^{23}$

\footnotetext{
22 Academia Nacional de la Historia, Actas capitulares (1947: 268-269).

${ }^{23}$ Archivo Histórico de la Provincia de Córdoba [AHPC], Archivo Gobierno [AG], tomo 31, legajo núm. 6, fs. 43-45. Este episodio se inscribe en la condición de José Giráldez, comerciante oriundo de Galicia, quien había sido recusado cuando fue propuesto como alcalde ordinario para el año 1808 por "tener pocas luzes [...] y que se sabe que ha venido una providencia de su acreedor y es hombre inquieto en los juegos". A pesar de la recusación en marzo de 1808 la designación de Giráldez fue confirmada por el gobernador intendente. Academia Nacional de la Historia, Actas capitulares (1947: 272-273).
} 
En diciembre de 1808 intervino en el conflicto el comandante Altolaguirre, quien dirigió un oficio al gobernador Gutiérrez de la Concha en el que hacía mención de otros hechos que evidenciaban los "procedimientos irregulares" del alcalde Giráldez que "recaen inmediatamente contra la autoridad de ese gobierno y de los infelices milicianos". Altolaguirre solicitaba al gobernador que tomara una "seria providencia" para que la autoridad capitular se "reconvenga en los límites que le corresponden". El oficio refiere específicamente a los "abusos" cometidos ante la fuga de reos de la cárcel de la Villa de la Concepción. Con relación a este hecho el alcalde Giráldez no había informado debidamente a la jefatura militar y tomó determinaciones que no le correspondían cuando responsabilizó y castigó al guardia que estaba de servicio al momento de la fuga exigiéndole un pago en dinero. Altolaguirre solicitaba que el dinero exigido fuera devuelto al soldado al tiempo que instaba al funcionario capitular a abstenerse de intervenir en las cuestiones relativas a los milicianos urbanos en "alivio de estos infelices que no tienen absolutamente quien los proteja por su suma indigencia e ignorancia". ${ }^{24}$

Estos episodios se encuadran en la antigua competencia entre ambos poblados, Concepción y La Carlota e incluían, como se expuso más arriba, la disputa por la sede de la comandancia de frontera. En la sesión capitular del 3 de octubre de 1809 se trató una presentación del síndico procurador de Concepción que sería enviada al gobernador intendente. ${ }^{25}$ En la misma se hacía referencia a los "perjuicios" que sufría el vecindario por parte de los "enemigos infieles", por lo que muchos de ellos abandonaban sus hogares o mudaban de domicilio en detrimento del "notable aumento de la población". Asimismo, otros individuos se encontraban deseosos de "venir a poblarse en esta villa por las muchas ventajas que proporciona la buena situación de ella". La escasez de hombres para la tropa, armas y municiones habían dejado desprotegida a la región que se "hace digna de las mayores atenciones". En este sentido se invocaba el nombre del fundador Sobre Monte, quien había dispuesto oportunamente la instalación de un fuerte principal para "seguridad de la frontera" ${ }^{26}$

Los episodios descriptos permiten advertir que los motivos de tensión eran recurrentes en estos espacios distantes de los centros decisionales de mayor jerarquía. No escapaban a la lógica de las rivalidades que caracterizaban

\footnotetext{
${ }^{24}$ AHPC, AG, tomo 31, legajo núm. 6, fs. 45-46.

${ }^{25}$ En sesión del 2 de octubre de 1809 el alcalde ordinario José Manuel Rodríguez propuso nombrar como síndico procurador interino a José de la Presentación Acosta en vistas de la ausencia de titular Pedro Martínez. Academia Nacional de la Historia, Actas capitulares (1947: 315-316). Los Acosta formaban parte de uno de los núcleos familiares de mayor arraigo en la zona. Los miembros de la familia y sus parientes colaterales ocuparon ininterrumpidamente puestos en el cabildo entre 1798 y 1810.

${ }^{26}$ Academia Nacional de la Historia, Actas capitulares (1947: 317-318).
} 
a las jurisdicciones de alcance político y territorial más amplio que también quedaban involucradas en las tensiones locales mediante la intervención individual o corporativa en los conflictos que estaban llamados a dirimir. En este contexto la alusión a la "peligrosidad" de la frontera se sostiene como un argumento que, más que un dato de la realidad, evidencia la competencia entre las autoridades coloniales.

\section{Consideraciones finales}

La fundación de fuertes que devinieron en villas al sur de la Intendencia de Córdoba obedeció a un nuevo proceso de organización política impulsado por la necesidad de efectivizar el poblamiento de la frontera que debía dotarse de fuerzas militares que estuvieran en condiciones de resistir las eventuales amenazas internas y externas. La situación de subordinación política que estos ámbitos poseían no impidió que construyeran sus respetivos espacios de poder en un proceso no exento de conflictos. Estos constituían el emergente de tensiones más profundas integradas a escalas territoriales más amplias. Las villas de frontera defendían sus respectivos argumentos para fortalecerse como entidades políticas en un contexto de marginalidad respecto de otros ámbitos decisionales.

El carácter corporativo que esgrimían los cabildos de la intendencia de Córdoba replicaba las lógicas de funcionamiento de esa institución en otras ciudades del virreinato: la conformación de un grupo de pobladores que pretendía construir un espacio político autónomo respecto de otras autoridades. Este proceso se advierte en la emergencia de los conflictos entre la autoridad capitular y la comandancia de frontera. La territorialidad era disputada entre los vecinos y la potestad militar impuesta por el reformismo borbónico a la que los primeros percibían como una amenaza al dominio corporativo. Este rasgo no parece ser privativo de las ciudades cabeceras de intendencia, como Córdoba, sino que se replica en los espacios marginales (Concepción, La Carlota).

En términos de Hespanha la miniaturización de los espacios políticos, profundamente imbricados con una concepción patrimonial del poder y un sentido tradicional de la comunidad son propios del antiguo régimen. En este sentido los conflictos señalados ponen de manifiesto la resistencia de las comunidades, en este caso materializadas en la acción corporativa de los cabildos, frente a las imposiciones de la política militar reformista.

Respecto de las autoridades centrales y frente a la intervención del poder del gobernador, de la audiencia o del virrey el cabildo supo distinguir entre aquellas disposiciones que favorecían o perjudicaban los intereses locales. Los episodios conflictivos narrados dan cuenta de que el fortalecimiento militar 
estaba avalado por la autoridad civil representada en el gobernador intendente. La anuencia y ratificación de la potestad de los comandantes de frontera y el respaldo a la comandancia de armas actuaba en detrimento de la práctica corporativa de los funcionarios de cabildo. Sin embargo, no siempre se resolvían los conflictos tal como pretendía hacerlo el gobernador. La resistencia de las autoridades capitulares se hizo manifiesta una y otra vez lo cual demuestra la complejidad de las dinámicas de poder que operaban a diferentes escalas territoriales.

Resulta pertinente la afirmación de Hespanha acerca del carácter plural del espacio político sobre el que pueden ejercerse poderes pertenecientes a diferentes jerarquías. El análisis realizado en este artículo permite afirmar que la preservación de los respectivos espacios de poder puede advertirse en dos planos: por una parte en los conflictos locales entre las autoridades cuya competencia jurisdiccional no poseía límites precisos dado que la corona había ideado un sistema institucional de superposición de funciones civiles, militares y judiciales. Por otro lado la competencia de poder se articulaba a escala virreinal e imperial con la rebeldía local que se manifestaba frente a las imposiciones de las políticas borbónicas. Las villas de frontera no escaparon a la lógica que prevalecía en las ciudades coloniales en las que las elites locales gozaban de prerrogativas y de poderes propios que no serían arrebatados fácilmente por la política centralizadora de la monarquía borbónica. La tradición de la miniaturización y patrimonialización del poder resistía esas imposiciones.

La afirmación de Garriga acerca de carácter negociador del reformismo borbónico que, en su búsqueda de consensos, debió tratar con las elites urbanas para hacer efectiva su decisión de establecimiento de plazas militares retroalimenta la discusión acerca del impacto de las reformas y de los conflictos que derivaron de los procesos de negociación.

En áreas de frontera como la estudiada en el presente artículo los núcleos de poblamiento eran de reciente fundación, sin embargo es posible advertir comportamientos tradicionalmente atribuidos a las élites de las ciudades españolas fundadas tempranamente en las que los grupos de poder locales se encontraban afianzados hacia finales del siglo XVIII. Los fundamentos de la cultura política hispana persistían pese a las nuevas medidas y los episodios narrados en el núcleo del trabajo dan cuenta de ello. Este es el universo de sentido que permite interpretar las disputas por la territorialidad en un espacio marginal del imperio.

Los movimientos juntistas producidos con la crisis de acefalía iniciada en 1808 dieron cuenta de que los poderes territoriales de las ciudades sostenían un conjunto de prácticas propias de una cultura política que tendría importantes consecuencias en el desarrollo ulterior del proceso revolucionario. Tradiciones y 
nuevos conceptos políticos confrontaron y disputaron espacios de legitimidad en el nuevo orden inaugurado en 1810.

\section{Bibliografía citada}

Abecasis, Alberto (2017). El cura Fassi...militante político. Río Cuarto: Miguel Ángel Tréspidi ediciones.

Academia Nacional de la Historia (1947). Actas capitulares de la Villa de la Concepción del Río Cuarto, 1798-1812, Buenos Aires: Kraft

Agüero, Alejandro (2018). “De privilegios fundacionales a constituciones. Territorio y jurisdicción en el origen de las provincias argentinas", en Agüero, Alejandro, Andréa Slemian y Rafel Diego-Fernández Sotelo (coords.) Jurisdicciones, Soberanías, Administraciones. Configuración de los espacios políticos en la construcción de los Estados nacionales en Iberoamérica, Córdoba: Universidad Nacional de Córdoba, El Colegio de Michoacán, pp. 441-480.

Archivo Municipal de Córdoba (1969). Actas Capitulares, Libros Cuadragésimo tercero y cuadragésimo cuarto (1805-1809), Córdoba.

Barriera Darío y Raúl Fradkin (coords.) (2016). Gobierno, justicias y milicias. La frontera entre Buenos Aires y Santa Fe (1720-1830), Facultad de Humanidades y Ciencias de la Educación, Universidad Nacional de La Plata.

Barriera, Darío (2012). “Tras las huellas de un territorio”, en Fradkin, Raúl (dir.). Historia de la Provincia de Buenos Aires. De la conquista a la crisis de 1820, tomo II, Buenos Aires: Edhasa, pp. 53-84.

Barrionuevo Imposti, Víctor (1986). Historia de Río Cuarto, tomo I. Buenos Aires: Gráfica Hornos.

Cantera, Carmen (2017). “Territorio y representaciones de la identidad en un espacio marginal: la villa de la Concepción del Río Cuarto entre la colonia y la revolución", ponencia presentada en las XVI Jornadas Interescuelas/Departamentos de Historia. Facultad de Humanidades de la Universidad Nacional de Mar del Plata.

Carbonari, María Rosa (1998). “Población y espacio en el Río Cuarto, fines del siglo XVIII", Cronía, UNRC, núm. 2, pp. 170-185.

Carbonari, María Rosa (2004). "Familias y estrategias de sobrevivencia en el mundo rural fronterizo del Río Cuarto. Fines del siglo XVIII e inicios del XIX", en Quarto Río. Revista de la Junta Municipal de Historia, núm. 7, pp. 107-124.

Carbonari, María Rosa (2009). "La elite riocuartense en tiempos del corrimiento fronterizo", en Segundas Jornadas Nacionales de Historia Social, La Falda, Córdoba. 
Carbonari, María Rosa (2010). "La construcción histórica de una sociedad otrora fronteriza. Cruces con la macro- historiografía", en Revista Escuela de Historia, núm. 1, pp. 1-23.

[disponible en: http://www.redalyc.org/articulo.oa?id=63822740011]

Carbonari, María Rosa (2011). “Entre la sierra y el llano, una historia no tan conocida del pasado colonial", en Prado, Daila y Miguel Tréspidi (comp.). Expedientes emanados del cabildo de la villa de la Concepción del Río Cuarto y su jurisdicción, 1798-1823. Río Cuarto: Universidad Nacional de Río Cuarto, pp. 2343.

Carbonari, María Rosa (2018a). "Un centro urbano en la frontera colonial. La villa de la Concepción", en Revista Sociedades de Paisajes Áridos y Semi-Áridos, vol. XI, Río Cuarto, pp. 145-166, [disponible en: http://www.hum.unrc.edu.ar/ojs/index.php/spas/article/view/698]

Carbonari, María Rosa (2018b). “Del surgimiento de la villa de la Concepción a la disolución del cabildo (1786-1824)", en Carbonari, María Rosa y Gabriel Carini (comps.) Río Cuarto y su región en clave histórica. Huellas, fragmentos y tensiones con los macro-relatos (1786-1955), Río Cuarto: UniRío, pp. $27-59$.

Carbonari, María Rosa e Iván Baggini (2004). “Población y familia en la región de Río Cuarto", en Quarto Río. Revista de la Junta Municipal de Historia, núm. 7, pp. 42-71.

Carbonari, María Rosa y Rosana Magola (2001-2002). “Prácticas mercantiles y familias campesina en la región de Río Cuarto a inicios del siglo XIX", en Cronía, UNRC, núm. 2, pp. 119-139.

Colom González, Francisco y Ángel Rivero (2015). El espacio político. Aproximaciones al giro espacial desde la teoría política, Barcelona: Anthropos.

Dainotto, Edgardo (2018). “El municipalismo de Ambrosio Funes. Prácticas e ideas acerca de los cabildos rioplatenses en tiempos de crisis: 1805-1809", en Prohistoria, núm. 30, pp. 27-69.

Estruch, Dolores (2014). "Construyendo jurisdicción, construyendo poder: límites, amojonamientos y competencias jurisdiccionales en la conformación del Jujuy colonial (siglos XVI-XVII)", en Benedetti, Alejandro y Jorge Tomasi Espacialidades altoandinas. Nuevos aportes desde la Argentina. Interacciones con el "mundo de afuera", tomo II, Buenos Aires: Editorial de la Facultad de Filosofía y Letras, pp. 75-116.

Garriga, Carlos (2009). "Patrias criollas, plazas militares: Sobre la América de Carlos IV", en Horizontes y Convergencias. Lecturas históricas y antropológicas sobre el derecho, [disponible en: http://horizontesyc.com.ar/?p=3551] 
Grenon, Pedro (1929). Internación de los prisioneros ingleses 1806-1807, Córdoba: Archivo de Gobierno, Documentos Históricos, vol. 15, Talleres Gráficos de la Penitenciaria.

Hespanha, António M. (1989). Vísperas del Leviatán. Instituciones y poder político (Portugal, siglo XVII), Madrid: Taurus.

Hespanha, António M. (1993). La gracia del derecho. Economía de la cultura en la Edad Moderna, Madrid: Centro de Estudios Constitucionales.

Molina, Eugenia (2016). "Justicia de proximidad, estrategias patrimoniales y capital simbólico. El caso de José Pescara, jurisdicción de Mendoza, Río de la Plata, 1762-1823", en Anuario IEHS, núm. 31 (2), pp. 9-32.

Olmedo, Ernesto y Marcela Tamagnini (2019). “La frontera sur de Córdoba a fines de la Colonia (1780-1809). Guerra, saber geográfico y ordenamiento territorial", en Fronteras de la Historia, vol. 24, núm. 1, pp. 36-72, [disponible en: http://www.scielo.org.co/pdf/frh/v24n1/2027-4688-frh-24-01-36.pdf]

Pérez Vejo, Tomás (2015). “La definición del espacio político en el nacimiento de la Modernidad. El caso hispanoamericano", en Colom González, Francisco y Ángel Rivero. El espacio político. Aproximaciones al giro espacial desde la teoría política, Barcelona: Anthropos, pp. 171-204.

Polimene, María Paula (coord.) (2011). Autoridades y prácticas judiciales en el Antiguo Régimen. Problemas jurisdiccionales en el Río de la Plata, Córdoba, Tucumán, Cuyo y Chile, Rosario: Prohistoria Ediciones.

Punta, Ana Inés (1997). Córdoba borbónica. Persistencias coloniales en tiempo de reformas (1750-1800), Córdoba: Universidad Nacional de Córdoba.

Punta, Ana Inés (2001). "Córdoba y la construcción de sus fronteras en el siglo XVIII", Cuadernos de Historia, núm. 4, Córdoba: UNC, pp. 159-194.

Punta, Ana Inés (2011). “Control social y políticas de frontera en la gobernación intendencia de Córdoba", en Sociedades de paisajes áridos y semiáridos, vol. V, Universidad Nacional de Río Cuarto, pp. 187-202, [disponible en file://C:/Users/iamerica.HUMANAS/Downloads/878-3228-1-PB.pdf]

Ramos, Virginia (2017). “El enemigo en casa: repercusiones, debates y conflictos facciosos ante la presencia de prisioneros ingleses en Córdoba del Tucumán (1806-1807)", en Anuario de la Escuela de Historia Virtual, núm. 11, pp. 1-22, [disponible en: http://revistas.unc.edu.ar/index.php/anuariohistoria]

Real Academia Española (1739). Diccionario de Autoridades, VI [disponible en http://web.frl.es/DA.html]

Real ordenanza para el establecimiento é instruccion de intendentes de exército y provincia en el virreinato de Buenos-Aires: año de 1782 [disponible en: https://archive.org/details/realordenanzapar00rode] 
Rustan, Elizabeth (2003). "Análisis demográfico de una villa de frontera de la gobernación intendencia de Córdoba del Tucumán: La Carlota según los padrones de 1789 y 1796", ponencia presentada en las Terceras Jornadas de Historia Económica, Montevideo.

Rustan, Elizabeth (2010). "La administración borbónica y su política diplomática de frontera. Frontera sur de la gobernación intendencia de Córdoba en el prisma del tratado con ranqueles en 1796", en Revista sociedades de paisajes áridos y semiáridos, vol. II, Universidad Nacional de Río Cuarto, pp. 17-38.

Rustan, Elizabeth (2011). “Jurisdicciones en cuestión. Cabildos y autoridades militares en la administración borbónica. Gobernación Intendencia de Córdoba a finales del siglo XVIII", en Polimene, María Paula (coord.). Autoridades y prácticas judiciales en el Antiguo Régimen. Problemas jurisdiccionales en el Río de la Plata, Córdoba, Tucumán, Cuyo y Chile, Rosario: Prohistoria Ediciones, pp. 139155.

Sábato, Hilda y Marcela Ternavasio (2015). “De las repúblicas rioplatenses a la República Argentina. Debates y dilemas sobre la cuestión republicana en el siglo XIX", en González Bernaldo, Pilar (dir.) Independencias iberoamericanas. Nuevos problemas y aproximaciones, Buenos Aires: Fondo de Cultura Económica, pp. 237-272.

Tamagnini, Marcela y Graciana Pérez Zavala (2010). El fondo de la tierra Destinos errantes en la Frontera Sur. Universidad Nacional de Río Cuarto, [disponible en: http://historiapolitica.com/datos/biblioteca/frontera tamagnaninyperezzavala.p $\underline{\mathrm{df}}$

Tamagnini, Marcela, Ernesto Olmedo y Alicia Lodeserto (2011). "Las armas en la frontera del Río Cuarto (1852-1870)", en Sociedades de paisajes áridos y semiáridos, Universidad Nacional de Río Cuarto, vol. IV, pp. 93-114, [disponible en

file:///C:/Users/iamerica.HUMANAS/Downloads/LAS ARMAS EN LA FRON TERA DEL RIO CUARTO.pdf]

Tell, Sonia (2008). Córdoba rural, una sociedad campesina (1750-1850). Buenos Aires: Prometeo.

Tío Vallejo, Gabriela (2016). Antiguo Régimen y Liberalismo. Tucumán, 1770-1830, Tucumán: Facultad de Filosofía y Letras: UNT.

Torre Revello, José (1946). El marqués de Sobremonte, gobernador intendente de Córdoba y Virrey del Río de La Plata, Buenos Aires: Peuser. 